Dhaka Univ. J. Biol. Sci. 31(1): 105-115, 2022 (January) DOI: https://doi.org/10.3329/dujbs.v31i1.57920

\title{
SCANNING ELECTRON MICROSCOPIC ANALYSIS OF CLAYS IN THE SOILS OF LOWER ATRAI BASIN OF BANGLADESH
}

\author{
ABMS IsLAM, ZH KHAN*, MS HUSSAIN AND MM UdDIN \\ Department of Soil, Water and Environment, University of Dhaka, \\ Dhaka-1000, Bangladesh
}

Key words: Clay minerals, Scanning electron microscope, Lower Atrai Basin

\begin{abstract}
Scanning electron microscopic (SEM) analysis of clay samples from four different soil series, viz. Binsara, Taras, Jaonia, and Manda in the Lower Atrai Basin of Bangladesh was performed to characterize the clay minerals. The micrographs of SEM were obtained at three different magnification levels, such as low $(2,000 x)$, medium $(5,000 x)$, and high $(10,000 x)$. The SEM proved to be ideally feasible for studying the size, shape, texture, and fabric of clay samples. The electron micrographs of clays in the Binsara soil series have shown well-formed six-sided flakes. These six-sided flake particles are $1: 1$ type (well-crystallized) kaolinite minerals. The lath-shaped, rounded flakes are the well crystallized 2:1 type illite mineral in clays of Taras and Jaonia soil series. The rod-shaped fluffy massesflakes are the indication of the presence of $2: 1$ type vermiculite in the clays of Manda soil series. The rounded particles in all soils are quartz grains.
\end{abstract}

\section{Introduction}

The scanning electron microscope (SEM) is one of the most versatile instruments that are uniquely feasible for studying the clay minerals in soil. The shape of the particles of various clay minerals has been determined by the use of SEM, and the SEM has shed light on the range of particle size of the components of clay. It produces a magnified, three-dimensional view of the unmodified clay surface with great depth of focus ${ }^{(1)}$. The surface configuration and three-dimensional view of clay minerals as observed in the micrographs of SEM are characteristically unique and typically distinctly different. These different morphologies can be used as criteria of characteristics for identifying individual species of clay minerals ${ }^{(2)}$. Besides SEM, there are many other methods for studying the clay minerals in soils, viz. X-ray diffraction (XRD), differential thermal analysis (DTA), transmission electron microscopy (TEM) and infrared spectroscopy (IR). Semiquantitative determination of soil clay minerals in Bangladesh was carried out using Xray diffraction techniques ${ }^{(3)}$. Clay mineralogical studies using other methods are still scarce. For better understanding of clay mineral configuration we used SEM in this study.

\footnotetext{
* Authors for correspondence : <khanzh_du@yahoo.com>
} 
SEM is a type of electron microscope that describes the sample by scanning it with a focused beam of electrons. The electrons interact with atoms in the sample that make up the sample producing various signals that contain information about the sample surface topography, composition and properties ${ }^{(4,5)}$. The electron beam is generally scanned in a raster scan pattern, and the beam's position is combined with the detected signal to produce an image. SEM can achieve resolution better than 1 nanometer. Specimens can be observed in high vacuum, low vacuum, wet conditions (in environmental SEM), and at a wide range of cryogenic or elevated temperatures ${ }^{(6)}$.

There are many published literature available on the applications of the SEM, but a few are on clay minerals. Identification of clay minerals by using SEM micrograph was carried out by Altschuler et al.(7) for central Florida clay; Wiewiora ${ }^{(8)}$ for Silesia, Poland clays; Schultz et al.(9) for Yucatan, Mexico clays; Yoshimura et al.(10) for Itoigawa, Japan clay; Herbillon et al.(11) for central Africa clay; Alam et al.(12) for Bangladesh clay; Rajkumar et al.(13) for West Bengal, Indian clay and Aleta et al.(14) for Liloan, Cebu, Philippine clay. Viewed from the micrographs of these authors, their clay specimens have rather defined outlines and relatively thin flakes and smooth planes. Borst and Keller ${ }^{(15)}$ studied many of the 49 reference clays of the API project. Gillot ${ }^{(16)}$ included only a few SEM micrographs of clays because at that time the instrument was not extensively applied in clay mineralogical research. However, we hope to show that the SEM, because of its unique operation and performance, can bring new dimensions to our understanding of clay minerals in the Lower Atrai Basin Soils.

The lower Atrai basin is one of the important physiographic units of Bangladesh. It is one of the large inland depressions of marshy land in northern Bangladesh and is locally known as Chalan Beel. Soils belonging to this physiographic unit are alluvial deposits of Atrai river and are fabulously fertile(17). They are heavily textured with silty clay to clay and are moderately acidic to neutral in reaction. Rice is the principal crop grown in this basin and Boro-fallow-fallow/Boro-Transplanted aman-fallow is the usual cropping pattern $^{(17)}$. Mineralogical investigation of this soil is essential for characterizing the minerals in soils as well as to ascertain the mineralogical impacts on soil management and productivity and also to understand the nature of mineral transformation or weathering.

Significant numbers of studies on clay minerals by SEM are available from different parts of the world. However, very limited research on electron micrographs of clay minerals in the soils of Bangladesh has been carried out(12). In the present study, an attempt has been taken to characterize the clays in the soils of Lower Atrai Basin of Bangladesh using SEM technique. 


\section{Materials and Methods}

Scanning Electron Microscopy aims to look at the structure and shape of the surface of clay mineral species. The principle of operation of the SEM is now quite familiar. An electron optical column, containing electromagnetic lenses, demagnifies an electron source in order to focus a fine beam that is scanned across the specimen surface in a rectangular raster in synchronism with the spot of a cathode ray tube ${ }^{(1)}$. The signal resulting from interaction of the beam with the specimen is collected by a suitable electron detector and used to modulate the Cathode Ray Tube (CRT) brightness. In most applications, it is the low-energy secondary electrons, which are thus used to form a picture of the specimen on the CRT face(5).

The most common SEM mode is the detection of secondary electrons emitted by atoms excited by the electron beam. The number of secondary electrons that can be detected depends, among other things, on the angle at which the beam meets the surface of specimen, i.e., on specimen topography. By scanning the sample and collecting the secondary electrons that are emitted using a special detector, an image displaying the topography of the surface is created. This image is called electron micrograph(6).

Lower Atrai Basin comprises the low-lying area between the Barind Tract and Ganges River Floodplain. It includes the Chalan Beel area. Most of this region lies in Naogaon and Natore districts (Fig. 1), while small areas extend into Rajshahi, Bogra and Sirajgang districts. The original area of the Lower Atrai Basin was about 108,800 ha which is reduced to about 36,800 ha at present because of rapid siltation. The low-lying plain land occupies most of the regions of the basin. Areas bordering the Ganges, Lower Atrai and a small part of the Jamuna Floodplains have some ridges penetrated into the basin and the relief is locally irregular near river channels ${ }^{(18)}$.

The soil samples used in this study were collected from the surface horizon $(0-6 \mathrm{~cm})$ of four soil series, namely Binsara, Taras, Jaonia, and Manda soil series from the Lower Atrai Basin of Bangladesh (Fig. 1). The environmental settings and some morphogenetic properties of the studied soils are presented in Table 1. The sample was prepared as described by Laird(19). Briefly, the soil was mechanically dispersed in distilled water and a bulk sample of the soil clay ( $<2 \mu \mathrm{m}$ particle size fraction) was separated by sedimentation and air dried. This $<2 \mu \mathrm{m}$ particle size fraction was saved as the whole clay fraction for scanning. In this study, the whole clay fraction ( $<\mu \mathrm{m}$ fraction) of the surface horizon of four soil profiles were scanned. The SEM was done for each sample at three different magnification levels, such as low $(2,000 x)$, medium $(5,000 x)$, and high $(10,000 x)$, so that we can find three electron micrographs of each sample at three different magnification levels.

SEM imaging was carried out in the Centre for Advanced Research in Sciences (CARS) of the University of Dhaka, Bangladesh. A JEOL JSM desktop scanning electron microscope (Fig. 2) was used to analyse the morphological features of the four different 
samples from different locations of Lower Atrai Basin. For SEM, the $\mathrm{H}_{2} \mathrm{O}_{2}$ treated samples were spotted onto a brass plate and the prepared samples were observed using a JEOL JSM-6490LA microscope. The SEM was operated at $20 \mathrm{kV}$ and the final aperture was removed to enhance signal collection.

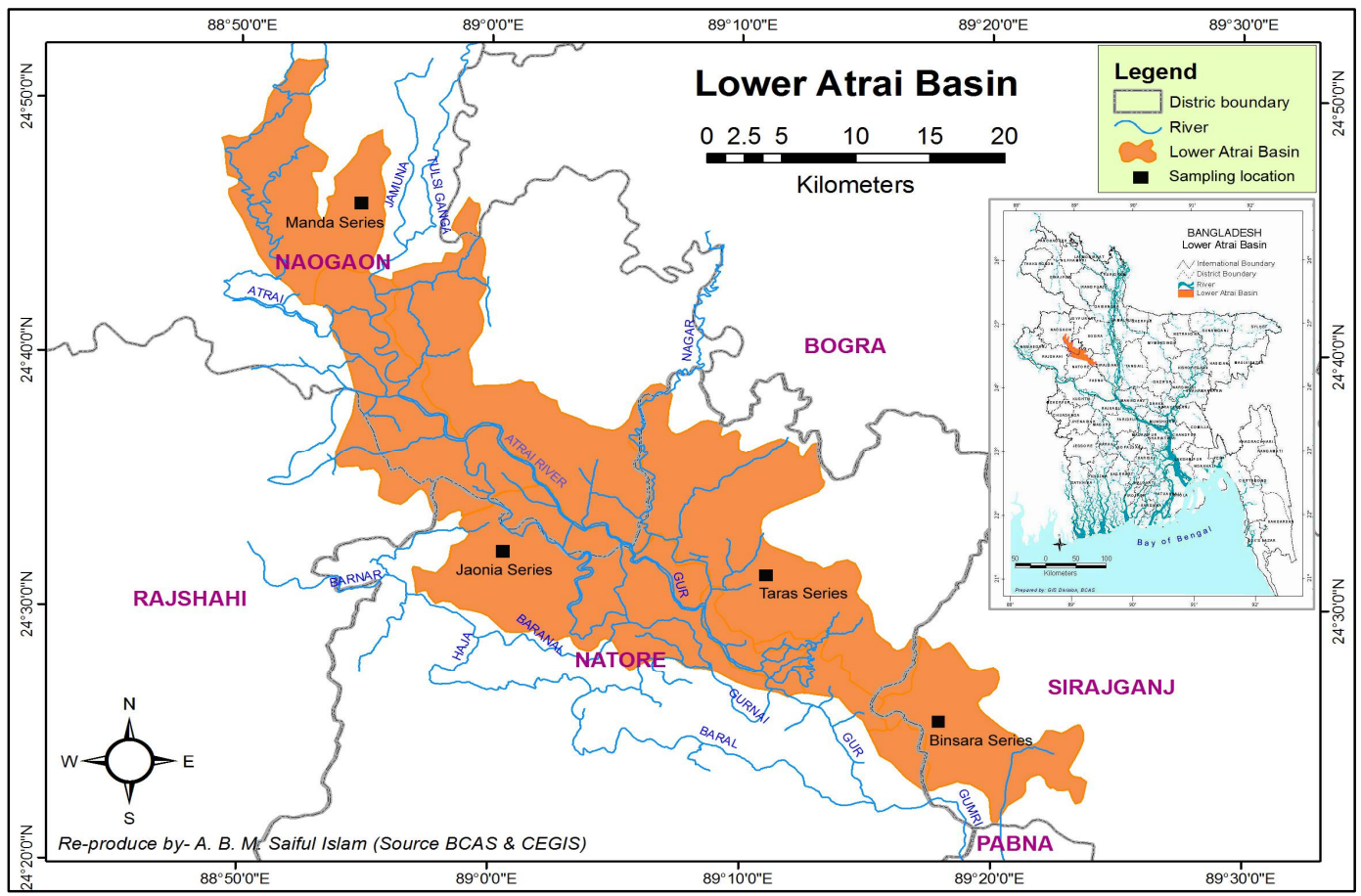

Fig 1. Map showing the sampling sites of the lower Atria Basin in Bangladesh.

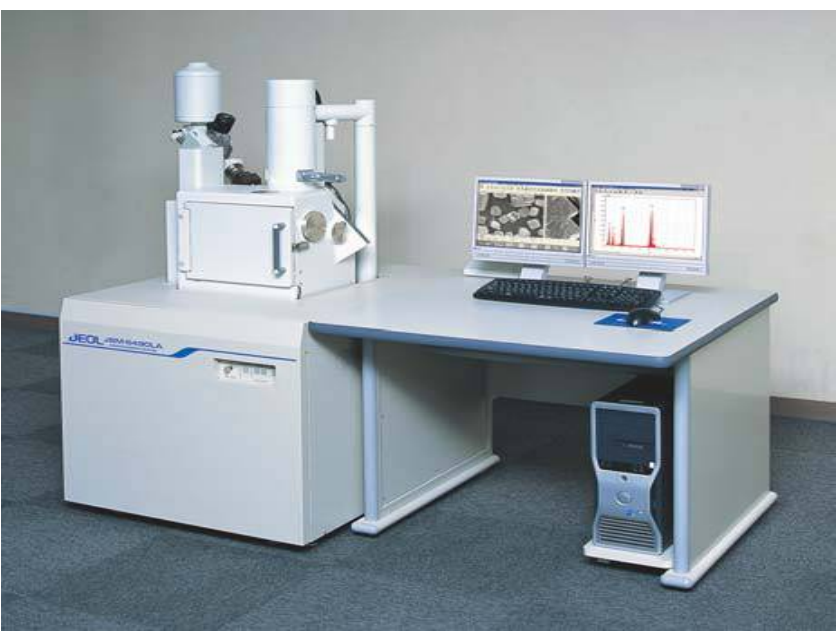

Fig 2. A JEOL JSM-6490LA Microscope used for this study. 
SCANNING ELECTRON MICROSCOPIC ANALYSIS OF CLAYS IN THE SOILS

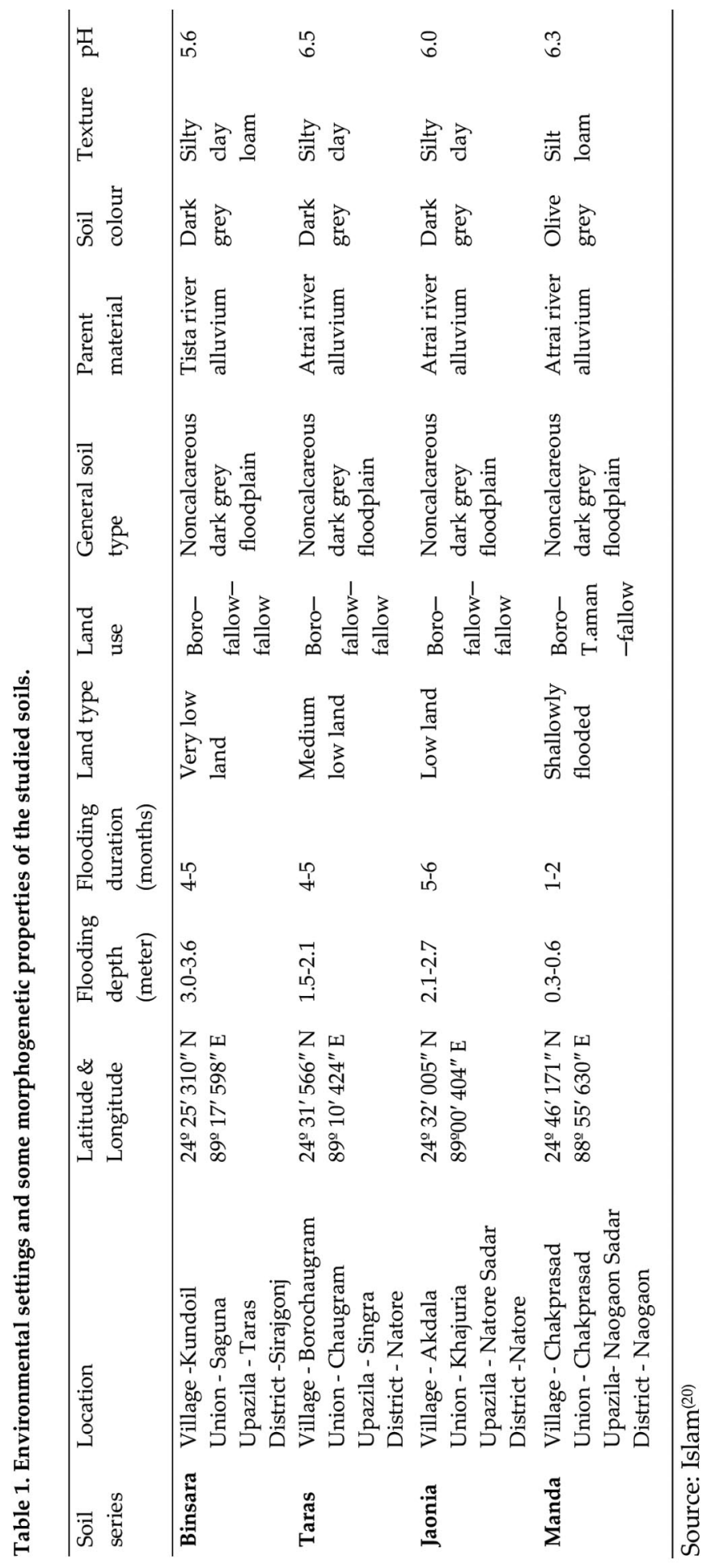




\section{Results and Discussion}

The scanning electron micrographs of the whole clay fraction of surface horizon of Binsara, Taras, Jaonia, and Manda soil series from the Lower Atrai Basin were presented in Plates 1-4.

The SEMs of the clays of surface soil of Binsara soil series (Plate 1) revealed small discrete particles scattered among the micro-aggregates. The low magnification $(2,000 x)$ scanning micrograph (Plate 1a) showed the overall appearance of the bulk sample of clay. High resolution (10,000x) SEMs of the same sample (Plate 1c) revealed two types of discrete particles. The first particle types are well-formed six-sided flakes, frequently with a prominent elongation in one direction. Certain of the edges of the particles were beveled instead of being at right angles to the flake surface. The electron micrographs of Binsara soil series exhibited the dimension of flake surfaces ranging from 0.3 to 4 microns and thickness from 0.05 to about 2 microns (Plate 1c). These six-sided flake particles are 1:1 type authigenic (well-crystallized) kaolinite minerals. Well-crystallized kaolinite particles showed well-formed six-sided flakes and poorly crystallized kaolinite particles showed less distinct six-sided flakes(21). The outline of kaolinite particles is not a welldefined hexagon because of the mechanical damages done during clay processing. The second particle type is composed of roughly equal dimensional particles with rounded edges and smooth surfaces, which are quartz and feldspar grains (Plate 1c). This observation confirmed well with those of Alam et al.(12), Rajkumar et al.(13) and Laird ${ }^{(19)}$.

The electron micrograph of the clay fraction of surface horizon of the Taras and Jaonia soil series (Plate $2 \& 3$, respectively) revealed numerous small discrete particles scattered among the micro-aggregates. The low magnification $(2,000 x)$ scanning micrographs (Plate 2a \& 3a) showed the overall appearance of the clay. High resolution $(10,000 x)$ SEMs (Plate 2c \& 3c) revealed three types of discrete particles. The first particle types were lath-shaped, rounded, poorly defined flakes, commonly grouped together in irregular aggregates. Some of the flakes have a distinct hexagonal outline and some other flakes show no evidence of hexagonal outlines. Such flakes are somewhat irregular but have well-defined outlines and are characterized by a uniform thickness. The thinnest flakes are approximately $30 \AA$. Many of the flakes have a diameter of 0.1 to 0.3 micron.

The lath-shaped, rounded flakes are the well crystallized 2:1 type illite minerals $(1,12,21,22)$. The second particle type is composed of roughly equal dimensional particles with rounded edges and smooth surfaces. Laird ${ }^{(19)}$ identified these small and rounded particles as quartz grains. The third particle type is composed of roughly equal dimensional particles with nodular surfaces. The nature of the nodular particles is not immediately apparent, but the nodular particles are obviously not phyllosilicates nor are they discrete quartz grains ${ }^{(21)}$. 


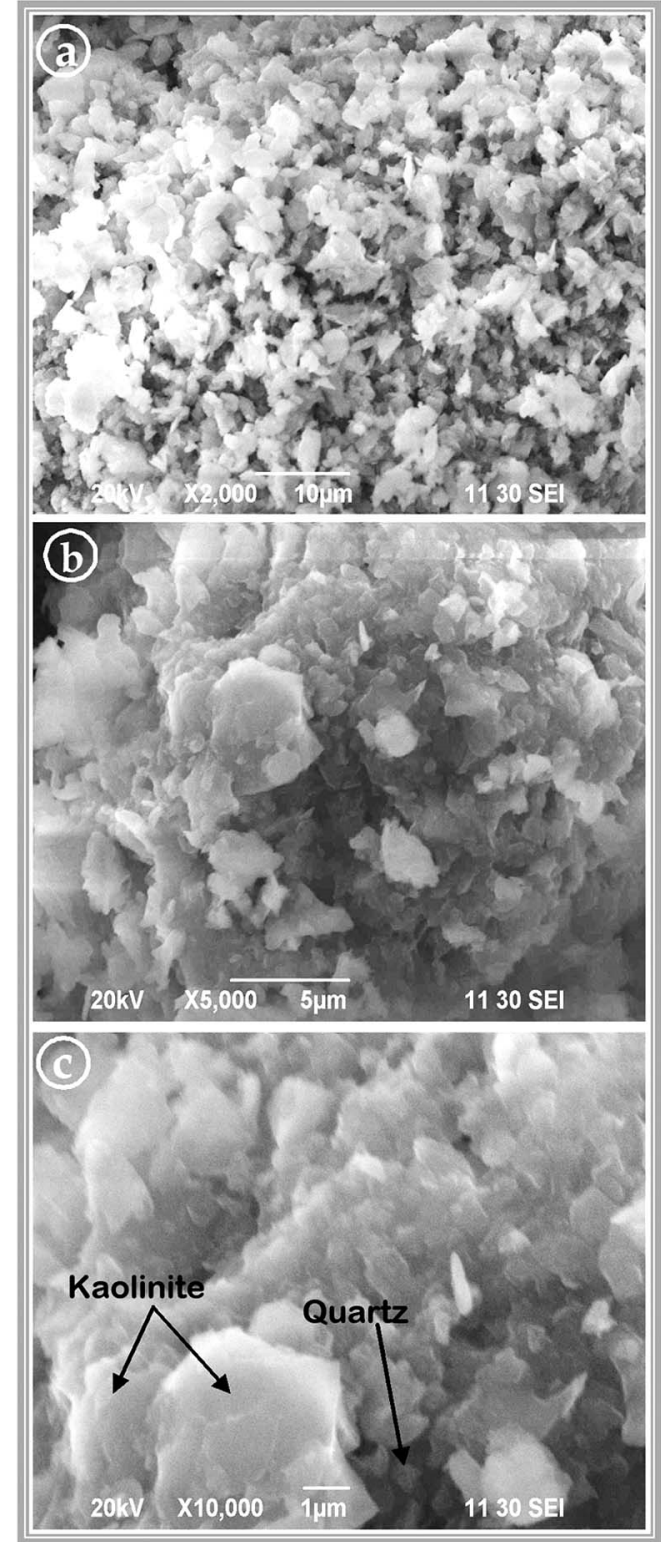

Plate 1. Scanning electron micrographs of the clay fraction of Binsara soil series from the Lower Atrai Basin: (a) Low (2,000x) magnification SEM, (b) Medium (5,000x) magnification SEM and (c) High $(10,000 x)$ magnification SEM

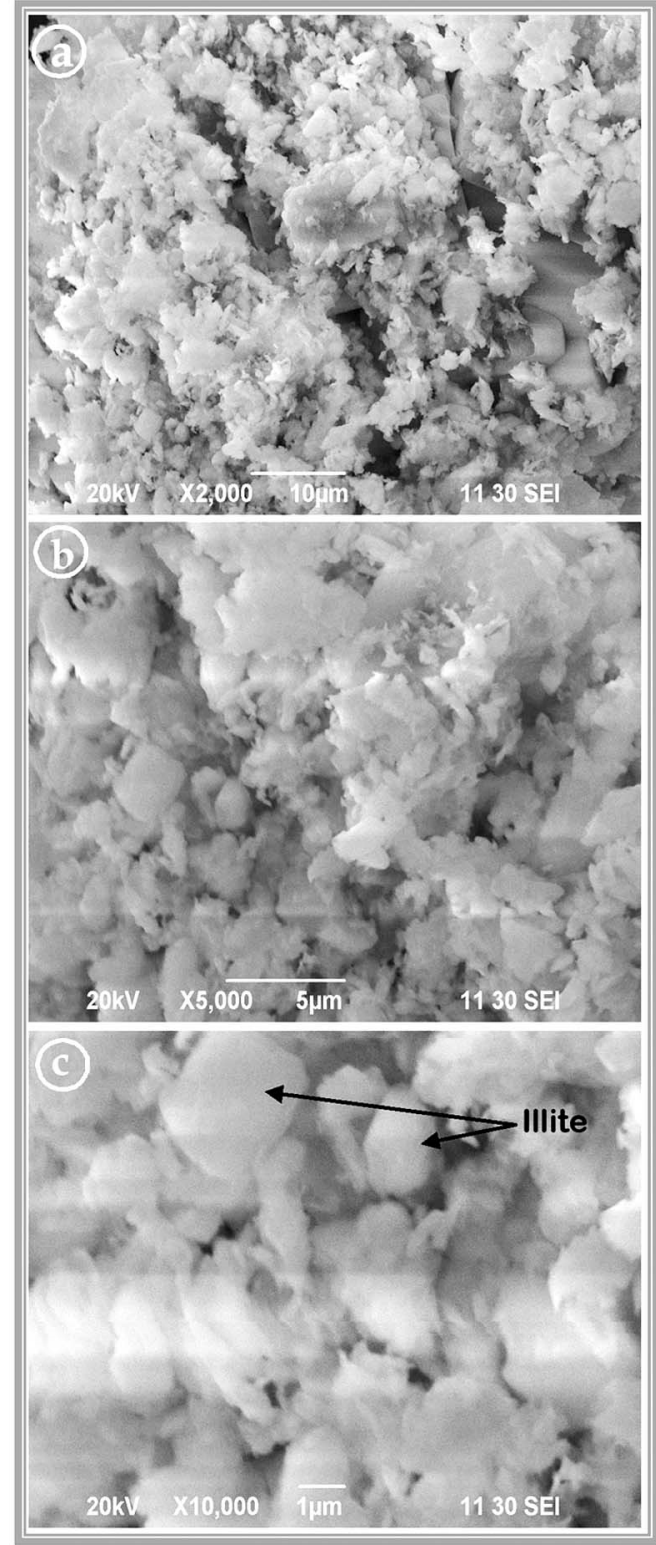

Plate 2. Scanning electron micrographs of the clay fraction of Taras soil series 1 from the Lower Atrai Basin: (a) Low (2,000x) magnification SEM, (b) Medium (5,000x) magnification SEM and (c) High $(10,000 x)$ magnification SEM.

The low magnification $(2,000 x)$ scanning micrograph of the Manda soil series (Plate 4a) showed the overall appearance of the bulk sample of clay fraction. The high resolution (10,000x) SEMs of the same samples (Plate 4c) revealed two types of discrete 


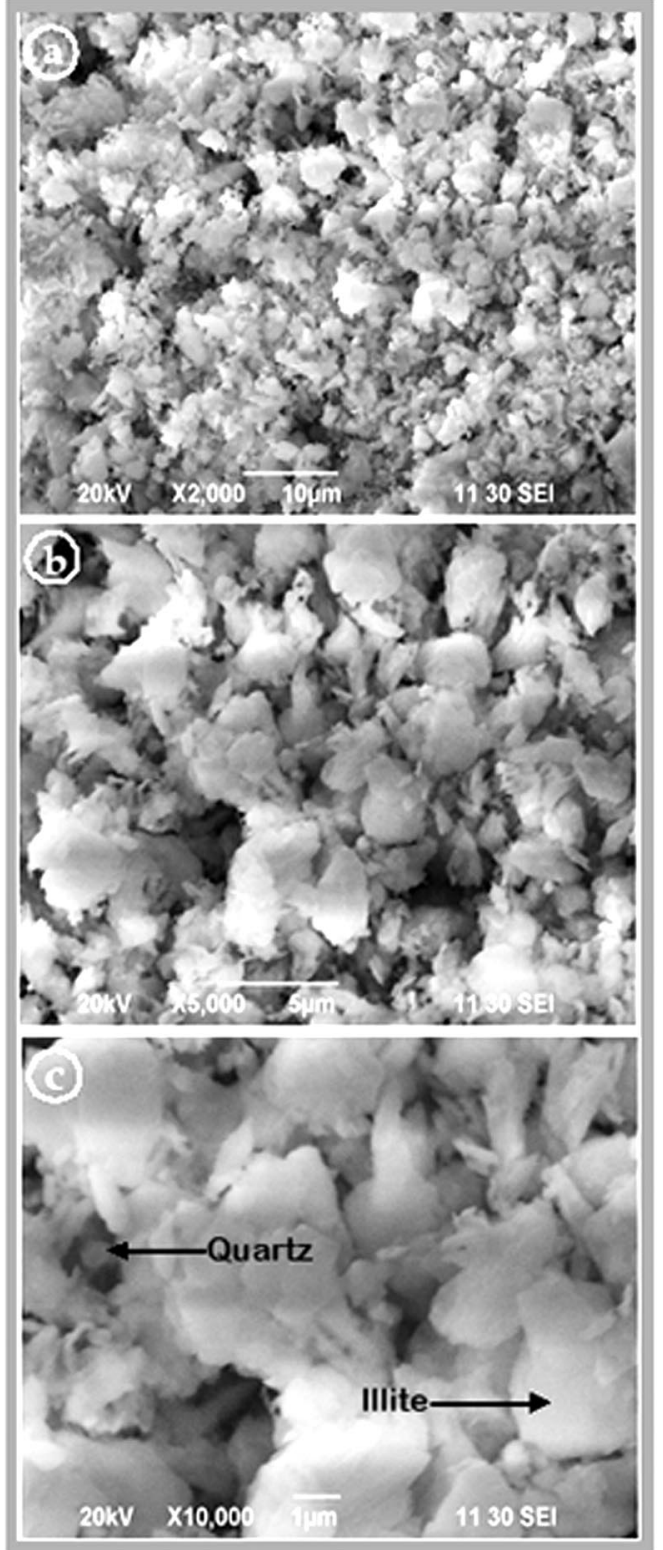

Plate 3. Scanning electron micrographs of the fine fraction of Jaonia soil series from the Lower Atrai Basin: (a) Low (2,000x) magnification SEM, (b) Medium (5,000x) magnification SEM and (c) High $(10,000 x)$ magnification SEM.
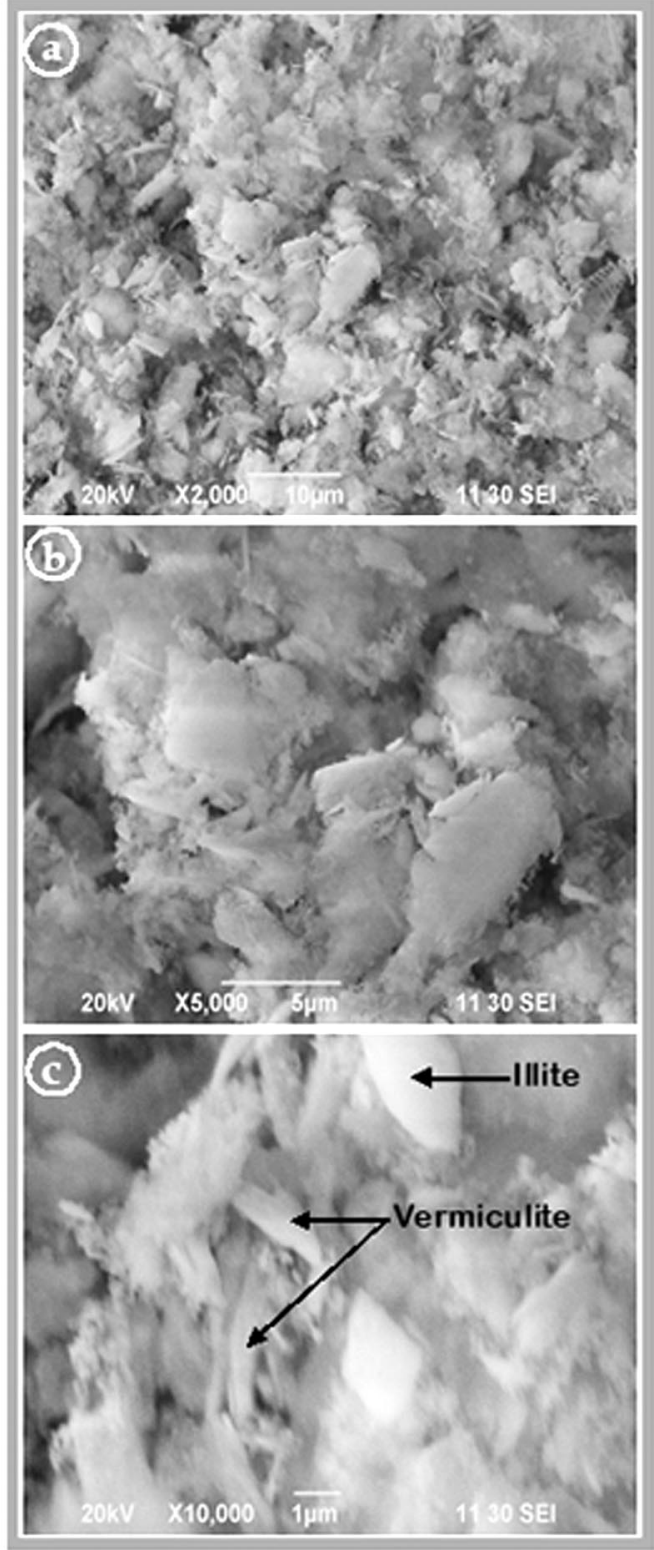

Plate 4. Scanning electron micrographs of the clay fraction of Manda soil series from the Lower Atrai Basin: (a) Low (2,000x) magnification SEM, (b) Medium (5,000x) magnification SEM and (c) High $(10,000 x)$ magnification SEM.

particles. The first particle types show irregular fluffy masses, elongate lath-shaped units, although flakes, needles, and rods of varying size. The particles appear to show striations parallel to the maximum dimension. The length of the laths is about five times the width 
dimension. The length of the laths ranges from 1 to 5 microns. An accurate estimation of the areal dimension of the flakes is difficult to obtain because of their irregularity. These rod-shaped fluffy mass flakes indicate that the minerals may be phyllosilicate 2:1 type vermiculite $^{(21,23)}$. The outline of vermiculite particles is not a well-defined flake because of the mechanical damages done during clay processing. The second particle type is composed of roughly equal dimensional particles with rounded edges and smooth surfaces. These rounded particles are quartz grains ${ }^{(13,19)}$.

The SEM photographs of the present study depict more or less similar morphological characteristics (shape and structure) of the clay mineral species in comparison to those studied by Herbillon et al.(11) for central Africa clay, Alam et al.(12) for Bangladesh clay, Rajkumar et al.(13) for West Bengal, Indian clay and Aleta et al.(14) for Liloan, Cebu, Philippine clay. Egashira and Yasmin (24) also found that illite was the predominant clay mineral in almost all floodplain soils of Bangladesh. Fanning and Keramidas ${ }^{(25)}$ pointed out that illite in most soils originated mainly from soil parent materials and tend to weather to other minerals with time. They generally are more prevalent in the clay mineralogy of younger and less weathered soils, such as Entisols, Inceptisols and Alfisols. Kaolinite was observed in all the soils but in small amount, although this mineral was dominant in some soils. Moslehuddin et al.(3) found similar results in their study. Dixon ${ }^{(23)}$ noted that kaolinite usually forms under well drained conditions through the weathering of feldspars. In the floodplain soils of Bangladesh, the kaolinite mineral is thought to be allogenic in nature and is believed to be derived from parent material(24,26). Saheed and Hussain ${ }^{(26)}$ noted that some in situ transformation might have taken place under the influence of local soil management practices. However, if any, such change is as small as the soils are in their incipient stage of development. Therefore, the clay minerals in the soils are most likely allogenic.

\section{Conclusion}

The present study has revealed that SEMs are very useful in identification of clay minerals of Lower Atrai Basin soils of Bangladesh. The speed and ease of operation, high magnification, and great depth of focus of SEMs make it uniquely suited to study the clay minerals. It is concluded that the SEM is almost indispensable for the study of clay mineral configuration, fabric, texture, and growth mechanics in the Lower Atrai Basin soils. The dominant clay mineral as depicted on SEM micrographs was illite with some kaolinite, 2:1 vermiculite and quartz. These clay minerals have rather defined outlines and relatively thin flakes and smooth planes indicating minimum transformation or weathering. Moreover, the obtained mineralogical composition will be helpful to predict soil behavior in relation to crop production in the Lower Atrai basin of Bangladesh. Advances in technology have made the SEM even more useful for studying the clay minerals in the soils of Lower Atrai Basin. 


\section{Acknowledgements}

We thank the authorities of Centre for Advanced Research in Sciences (CARS) and Department of Soil, Water and Environment at the University of Dhaka, Bangladesh for the use of their facilities.

\section{References}

1. Bohor BF and RE Hughes 1971. Scanning electron microscopy of clays and clay minerals. Clays and Clay Minerals. 19: 49-54.

2. Keller WD, RC Reynolds and Inoue Atsuyuki 1986.Morphology of clay minerals in the smectite-to-illite conversion series by scanning electron microscopy. Clays and Clay Minerals. 34(2):187-197.

3. Moslehuddin AZM, SMM Alam and K Egashira 2006. Mineralogy of soils from different agroecologicl regions of Bangladesh: Region 5 - Lower Atrai Basin and region 6 - Lower Purnabhaba Floodplain. Clay Sci. 13: 35-41.

4. Echlin P 2009. Handbook of sample preparation for scanning electron microscopy and X-Ray. E-book. New York, NY, USA: Springer.

5. Erdman N, DC Bell, R Reichelt 2019. Scanning electron microscopy. In: Hawkes PW, Spence $\mathrm{JCH}$, eds., Springer handbook of microscopy. Springer handbooks. Cham: Springer. doi: 10.1007 978-3-030-00069-1_5.

6. McMullan D 1995. Scanning electron microscopy 1928-1965. Scanning. 17(3): 175-185.

7. Altschuler ZS, EJ Dwornik and J Kramer 1963. Transformation of montmorillonite to kaolinite during weathering. Science. 141: 148-152.

8. Wiewiora A 1973. Mixed-layer kaolinite-smectite from Lower Silesia, Poland: final report. Proc. Intern. Clay Conf., Spain, pp. 75-88.

9. Schultz LG, AO Shepard, PD Blackmon and HC Starkey 1971. Mixed-layer kaolinitemontmorillonite from the Yucatan Peninsula, Mexico. Clays and Clay Minerals. 19: 137150.

10. Yoshimura T, S Wakabayashi and J Akai 1979. Kaolinite-montmorillonite mixed-layer minerals in the weathering zone of acid clay deposits from Itoigawa, central Japan. KobutsugakuZasshi (Journal of Mineralogical Society of Japan). 14: 42-57.

11. Herbilloan AJ, R Frankart and L Vielvoye 1981. An occurrence of interstratified kaolinitesmectite minerals in a red-black soil toposequence. Clay Minerals. 16: 195-201.

12. Alam LM, T Kakoi, N Miyauchi and A Shinagawa 1993. Electron microscopic observation of clays of calcareous and non calcareous soils in Bangladesh. South Pacific Study. 13(2): 161172.

13. Rajkumar K, AL Ramanathan, PN Behera and S Chidambaram 2014. Preliminary studies on the characterization of clay minerals in the Sundarban mangrove core sediments, West Bengal, India. Arab J Geosci. 7: 537-544.

14. Aleta, DGA, K Tomita and M Kawano 1999. Mineralogical and characterization studies of the mixed layer kaolinite/smectite clay deposit in Liloan, Cebu Province, Philippines. Clay science. 11: 11-29. 
15. Borst RK and WD Keller 1969. Scanning electron micrographs of API reference clay minerals and other selected samples: Proc. Intern. Clay Conf. Tokyo, Israel University Press, Jerusalem. 1: 871-901.

16. Gillot JE 1969. Study of the fabric of fine-grained sediments with the scanning electron microscope: J. Sediment. Petrol. 39: 90-105.

17. Islam ABMS, ZH Khan and AR Mazumder 2014. Pedogenesis and characterization of some soils from the Chalan beel of Bangladesh. J. Asiat. Soc. Bangladesh, Sci. 40(2): 271-281.

18. Islam S 2003. Banglapedia, National encyclopedia of Bangladesh. Vol. 1-10. Asiatic society of Bangladesh, Dhaka.

19. Laird D 2001. Nature of clay-humic complex in an agricultural soil: II. Scanning electron microscopy analysis. Soil Sci. Soc. Am. J. 65: 1419-1425.

20. Islam ABMS 2017. Morphogenetic and Taxonomic Characterization of the Lower Atrai Basin Soils of Bangladesh. PhD Dissertation, University of Dhaka. p. 270.

21. Grim RE 1953. Clay Mineralogy. McGraw-Hill book company, Inc. Printed in the USA. pp. 106-125.

22. Borst RK and WD Keller 1969. Scanning electron micrographs of API reference clay minerals and other selected samples: Proc. Intern. Clay Conf. Tokyo, Israel University Press, Jerusalem. 1: 871-901.

23. Dixon JB 1977. Kaolinite and serpentine groups of minerals. In: Minerals in Soil Environments. pp. 357-403. Soil Sci. Soc. Am., Madison, Wisc. USA. p. 795.

24. Egashira K and M Yasmin 1990. Clay mineralogical composition of floodplain soils of Bangladesh in relation to physiographic units. Bull. Inst. Trop, Agr., Kyushu Univ. 13: 105126.

25. Fanning DS and VZ Keramidas 1977. Mica. In: Dixon JB and SB Weed (Eds.) Minerals in Soil Environments. pp. 195-258. Soil Sci. Soc. of Am., Madison, Wisconsin, U.S.A. p. 795.

26. Saheed SM and MS Hussain 1992. Wetland soils of Bangladesh. In: JM Kimble (1992); Characterization, Classification and Utilization of Wet Soils. USDA, Soil conservation service. National soil survey centre. Lincoln, NE. pp. 220-229. 